\title{
AVALIAÇÃO DE UM SISTEMA ALTERNATIVO \\ PARA TRATAMENTO DE EFLUENTE \\ DOMÉSTICO E PLANEJAMENTO PARA \\ CONSCIENTIZAÇÃO DA COMUNIDADE
}

\section{EVALUATION OF AN ALTERNATIVE SYSTEM FOR TREATING DOMESTIC EFFLUENT AND PLANNING FOR A COMMUNITY AWARENESS}

HELOISA REGINA TURATTI SILVA, DRA. | UNISUL

PAOLA EGERT, DRA | UNISUL

MARIA IZABEL WILLEMANN | UNISUL

\begin{abstract}
RESUMO
A Educação Ambiental constitui uma forma bastante abrangente de "educar" e deve acontecer por meio de processos onde o indivíduo e a coletividade construam valores sociais, conhecimentos, habilidades, atitudes e competências voltadas para a conservação do meio ambiente. Na área de saneamento básico a educação ambiental desempenha um papel de grande importância, uma vez que a falta do conhecimento e habilidades adequadas geram sérios malefícios para a saúde e o bem-estar da população. No presente trabalho foi executado e avaliado um método alternativo para tratamento de efluente doméstico, ideal para comunidades distantes de centros urbanos e sem sistema de tratamento de esgoto. Através dos resultados alcançados, juntamente as informações técnicas apresentadas foi possível pensar em uma estratégia para levar o conhecimento a toda a comunidade. Assim, posteriormente, uma cartilha educativa sobre a importância do saneamento básico, bem como sobre a importância de um tratamento de esgoto, suas vantagens, desvantagens e comparativo econômico com outros modelos de tratamento de esgoto foi elaborada, para que órgãos públicos possam trabalhar com a população de forma a alcançar uma conscientização sobre a importância do assunto para melhorar a vida e a saúde das pessoas.
\end{abstract}

PALAVRAS CHAVE: Educação Ambiental; Saneamento Básico; Esgoto de bambu

\begin{abstract}
Environmental Education is a very comprehensive way of "educating" and it should happen through processes where the individual and the community build social values, knowledge, skills, attitudes and competence aimed at the conservation of the environment. In the area of basic sanitation, environmental education develops a major role, since the lack of adequate knowledge and skills creates serious harm to the health and well-being of the population. In this work, a alternative method for treatment of domestic wastewater treatment was carried out and evaluated, ideal for communities far from urban centers and without sewage treatment system. Through the results achieved, together with the technical information presented, it was possible to think of a strategy to bring knowledge to the whole community. So, later, a educational hornbook on the importance of basic sanitation, as well as on the importance of a sewage treatment, its advantages, disadvantages and economic comparative with other models of sewage treatment has been elaborated, so that public agencies can work with the population in order to reach an awareness about the importance of the subject to improve the life and health of people.
\end{abstract}

KEY WORDS: Environmental Education; Basic sanitation; Bamboo sewage 


\section{INTRODUÇÃO}

O Saneamento Básico é um assunto que engloba diferentes áreas do conhecimento, tais como saúde, social e tecnológica. A falta de um saneamento adequado pode causar diferentes doenças de veiculação hídrica, sendo uma das mais recorrentes a diarreia em crianças, mas a precariedade destes serviços também contribui para a incidência de óbitos com outras causas, em comunidades (Aisse, 2000; Garcia, 2017; Machado, 2015).

Os riscos para a saúde gerados pelo saneamento inadequado ou inexistente estão relacionados principalmente com a ingestão de água contaminada, através de contato direto, ou por meio de vetores que necessitam da água em seu ciclo biológico (Brasil, 2013). Estes derivam de poluentes químicos, efluentes industriais, ou causados por acidentes ambientais.

Vale destacar também que a deficiência dos serviços de saneamento básico tem estreita relação com a degradação do meio ambiente. Garcia (2017) comenta que a falta de saneamento é a principal causa de degradação ambiental das bacias hidrográficas brasileiras, principalmente daquelas situadas em grandes metrópoles. Garcia (2017) ainda comenta que segundo dados do Instituto Brasileiro de Geografia e Estatística - IBGE, (2010), apesar do abastecimento de água potável no Brasil estar em torno de $99 \%$ dos municípios, a coleta de esgoto sanitário está com valores bem inferiores, cerca de $55 \%$ dos municípios, assim como o tratamento de esgoto sanitário - com apenas $28 \%$ dos municípios.

Levando em consideração este baixo índice de tratamento de esgoto sanitário, é importante que busquemos alternativas viáveis de solução ao problema e que estes tenham aceitação pela comunidade. Em um momento em que toda a sociedade busca por métodos de preservação do meio ambiente, novas técnicas para o tratamento e a reutilização de efluentes são de grande valia.

Embora algumas técnicas já tenham sido criadas e com resultados promissores, ainda prevalece uma forte resistência por parte de muitas comunidades, prejudicando sua implantação, principalmente quando envolve algum investimento financeiro por parte do usuário. Os tratamentos alternativos de esgoto são exemplos de técnicas criadas e motivadas, principalmente, por uma preocupação ambiental (Dias, 2016; Mielbratz, 2016; Machado, 2015; Souza, 2010; Fagundes, 2009). Estes tratamentos alternativos podem trazer solução para comunidades que não apresentam condições financeiras para instalação de um sistema de tratamento de esgoto convencional.

Este é o caso da comunidade escolhida para o estudo aqui apresentado, ou seja, o município de Rio Fortuna, no estado de Santa Catarina, onde uma grande parte da população, que se localiza em zonas rurais da cidade, não tem acesso a um tratamento adequado para o esgoto doméstico. Este município está situado a $117 \mathrm{~km}$ de Florianópolis, capital do estado de Santa Catarina (SC), possuindo uma área territorial de $302 \mathrm{~km}^{2}$ e, pelo censo de 2010, segundo o IBGE, uma população de 4.446 habitantes.

Segundo o IBGE, 30,6\% das residências possuem esgoto sanitário adequado, ou seja, fossa filtro e sumidouro.

Além disso, é importante comentar que esta região é abastecida pelo Rio Fortuna e, em seu percurso, segundo uma pesquisa feita pela prefeitura Municipal, no ano de 2010, havia lançamentos de esgotos domésticos provenientes da drenagem pluvial, de dejetos de animais da área rural e contaminação por defensivos agrícolas, alguns sem qualquer tratamento para minimizar a poluição. Para trazer uma alternativa de solução a este problema, um tratamento de esgoto alternativo foi proposto por órgãos estaduais, e será aqui apresentado.

Para obter sucesso com a comunidade o tratamento deve ser simples, de fácil entendimento na construção, compacto e de baixo custo. Além disso, o município tem solo argiloso, lençol freático alto e topografia irregular, logo o tratamento deve se adaptar também a essas condições.

Uma sugestão que se adaptaria bem a estas condições é o tratamento de esgoto com recheio de bambu (Quege, 2013; Souza, 2010, Feng, 2008; Brito, 2007; Tritt, 2003), que se trata de um tratamento em subsolo, de baixo custo, fácil execução e manejo, e seguro em relação ao lençol freático, pois não entra em contato com o solo, não sendo necessário o uso de sumidouro.

Com o objetivo de investigar o investimento, dificuldades e qualidade, este trabalho apresenta a instalação de um tratamento alternativo para efluente doméstico, em uma residência unifamiliar do município de Rio Fortuna.

A finalidade do uso do saneamento básico está em proteger e melhorar as condições de vida da população. As ações de saneamento precisam de uma adequação ao lugar onde serão realizadas, respeitando as características socioculturais, econômicas e ambientais do local, buscando tecnologias alternativas que sejam apropriadas a cada tipo de comunidade. Além disso, é necessária a aceitação da comunidade à nova proposta, pois isto implica em investimento inicial e consumo de tempo.

Neste sentido destaca-se o papel da educação como importante estratégia de proteção da saúde da comunidade. A transformação dos sistemas sociais só é possível mediante a transformação dos seres humanos que os configuram. O entendimento da comunidade e a participação na vida social são considerados ações importantes para a transformação 
da realidade. Portanto, é imprescindível desenvolver ações educativas que possibilitem a compreensão sistêmica que a questão exige e estimular a participação popular, engajada e consciente, no enfrentamento dessa questão.

Nesse contexto, a Educação Ambiental em saneamento constitui-se numa promissora possibilidade de atuação que busca, por meio de ações articuladas, oportunizarem a emancipação dos atores sociais envolvidos e, com isso, despertar o protagonismo popular na condução das transformações esperadas.

O processo de educação ambiental em sua vertente transformadora acontece no momento em que a população, ao olhar de forma crítica para os aspectos que influenciam sua qualidade de vida, reflete sobre os fatores sociais, políticos e econômicos que originaram o atual panorama e busca atuar no seu enfrentamento (Pinto, 2017; Fontes, 2017; Mesquita, 2016; lorio, 2009; Silva, 2009; Campos, 2006; Bolscho, 2006; Dias, 2002).

Portanto, este trabalho também apresenta um planejamento em Educação Ambiental com esta comunidade, que como a maioria da população mundial, sofre com a carência no saneamento básico e seus benefícios. Como estratégia principal para alcançar a maioria da população foi montada uma cartilha demonstrando a importância do novo tratamento e ensinando a executar esta técnica de forma simples (Mesquita, 2016, Lisbôa, 2008). Assim, a estratégia usada no desenvolvimento deste trabalho foi a união da importância absoluta do saneamento com a importância da educação ambiental.

\section{PROCEDIMENTOS METODOLÓGICOS}

\subsection{Apresentação do Município de Rio Fortuna} O município de Rio Fortuna localiza-se, conforme Figura 1, na região sul do estado de Santa Catarina, confrontando-se ao Norte com Santa Rosa de Lima; ao Sul com Grão Pará, Braço do Norte e Armazém; a Leste com São Martinho, e a Oeste com Urubici e Grão Pará.

A água do município de Rio Fortuna é captada para tratamento e distribuição no Córrego São Marcos, manancial pertencente à Bacia Hidrográfica do Rio Tubarão. As margens dos córregos encontram-se desprotegidas e as atividades agrícolas são intensas, contribuindo para a degradação ambiental, não isentando o manancial de possíveis contaminações. A qualidade da água do manancial se enquadra na classe I do Conama (RESOLUÇÃO № 357), apropriada para ser tratada para o consumo humano. Atualmente o ponto de captação apresenta, mata de alto porte e de difícil acesso.

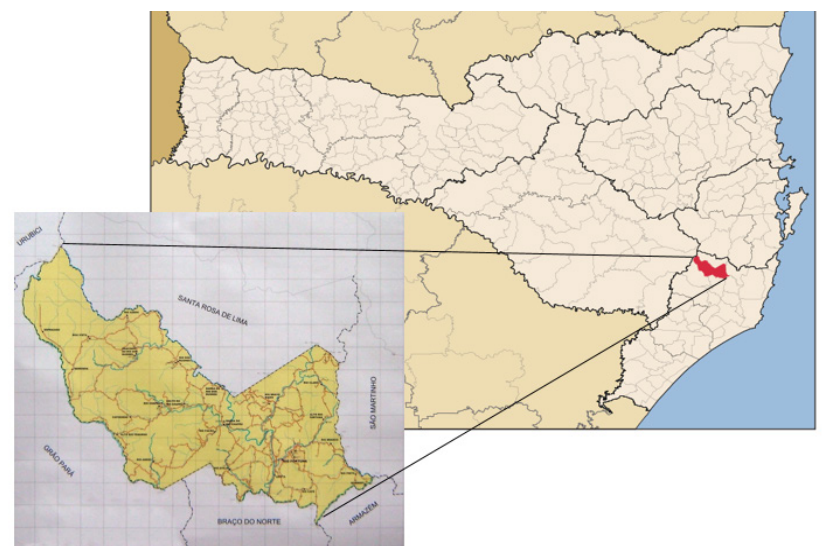

Figura 1 - Localização do Município de Rio de Fortuna no estado de Santa Catarina Fonte: Adaptado de http://www.riofortuna.sc.gov.br/(2017).

\subsection{Método}

O trabalho consiste em instalar um sistema alternativo para tratamento de efluente em uma residência unifamiliar do município de Rio Fortuna. O tratamento escolhido foi o processo de filtro com recheio de bambu conforme comentado na introdução. Além da praticidade em adquirir os materiais, o tempo e o custo de mão de obra foram determinantes na escolha do método.

Com o intuito de validar a técnica e economicamente o sistema de filtro de bambu, foi realizado o orçamento sobre o custo de execução deste tratamento alternativo e comparado com o orçamento realizado em um tratamento de esgoto convencional (fossa/filtro).

Além disso, foi realizado também alguns ensaios de análise química no Centro Tecnológico Amael Beethoven Villar Ferrin de Tubarão/SC: potencial hidrogeniônico-pH (Método Potenciométrico); Cor e Turbidez (Spectroquant NOVA-60-MERCK); Demanda Bioquímica de Oxigênio-DBO (Método Respirométrico - oxitop); Demanda Química de Oxigênio-DQO (Refluxo com dicromato de Potássio) para observar os resultados obtidos com o processo alternativo.

\subsection{Instalação do sistema alternativo para tra- tamento de efluente doméstico}

Para uma avaliação do sistema alternativo de tratamento de efluente foi feita a instalação de um filtro com recheio de bambu em uma residência unifamiliar do município de Rio Fortuna.

De início, como nos mostra a figura 2a, foi escavado uma vala com aproximadamente 3 metros de comprimento com 1,5 metros de largura. Esta dimensão foi baseada nas dimensões dos tubos de concreto, que possuíam aproximadamente $80 \mathrm{~cm}$ de diâmetro cada. A figura $2 \mathrm{~b}$ mostra o bambu, cortado em pequenos pedaços de aproximadamente $15 \mathrm{~cm}$ cada, e alguns com o diâmetro interno do tubo. 

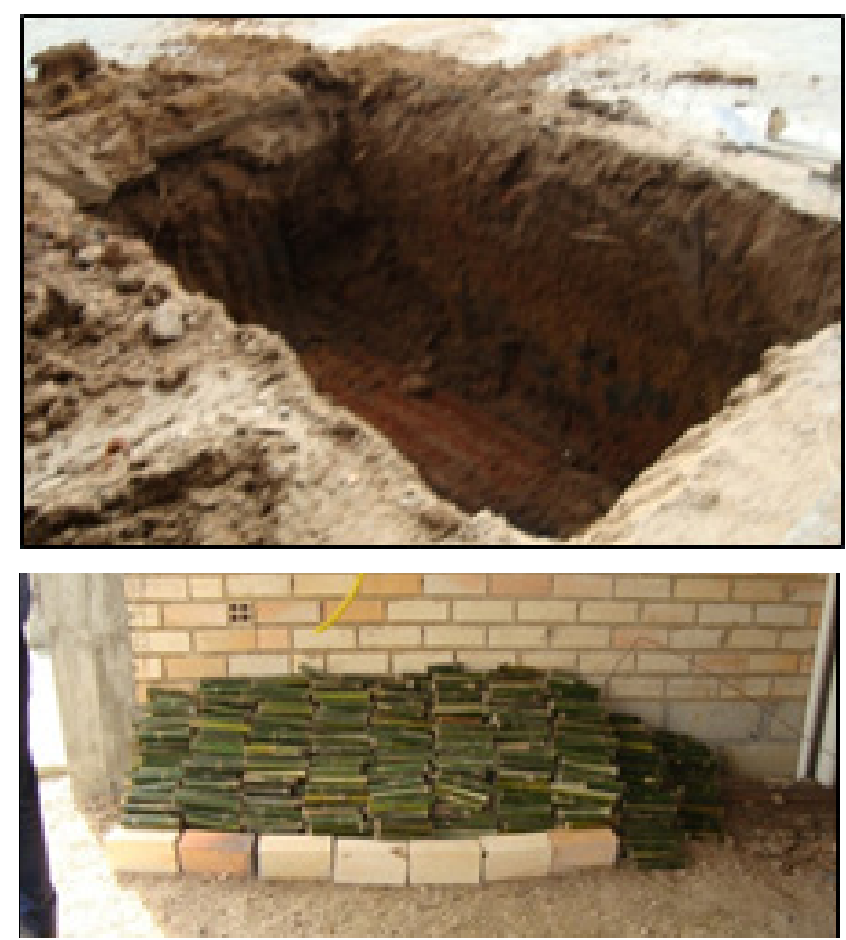

Figura 2 - (a) Vala escavada para o início da execução (b) Pequenos pedaços de bambu para a execução do tratamento.

Fonte: Autores (2016).

A tubulação de PVC é utilizada para o efluente passar de um tubo para o outro e, após, para a drenagem urbana. São utilizados alguns joelhos e canos de diâmetro de $100 \mathrm{~mm}$.

Com os materiais selecionados, inicia-se a execução. Inicialmente são colocados fundos feitos de concreto por onde o efluente entra, passando por uma tampa feita de bambu até chegar ao filtro. Esses fundos possuem furos, por onde são colocados os tubos de PVC. A Figura 3a mostra os três fundos colocados em locais estratégicos dentro da vala. Os locais onde se encontram os tubos são escolhidos devido a facilidade de manuseio dos mesmos na hora da execução.

São encaixados então, os tubos e, feito com bambu, uma tampa, onde o efluente passa antes de chegar ao filtro. Esta tampa já inicia o tratamento de filtragem do efluente. A figura 3b mostra a colocação dos tubos e as tampas de bambu sendo construídas.

Após a colocação das tampas de bambu, são inseridos os tubos para a passagem do efluente. O efluente entra no tratamento pela parte inferior através do tubo de PVC, passando pela tampa de bambu e então pela filtragem dos pedaços de bambu de $15 \mathrm{~cm}$. Para os dois primeiros tubos, inicia-se o processo de colocação dos pequenos pedaços de bambu, que servem para alojamento das colônias de bactérias (Brito et al., 2007) e vedação do tubo com uma tampa de concreto. A figura 4 demonstra esse processo sendo executado.
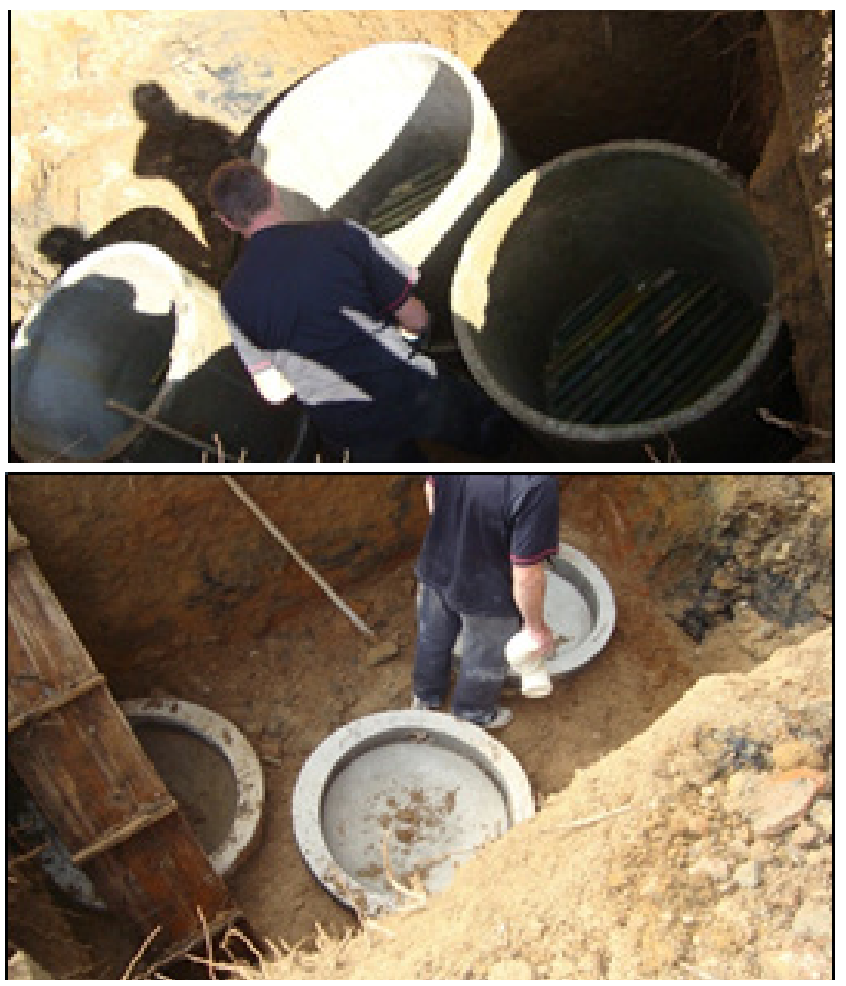

Figura 3 - a) Fundos sendo colocado na vala. b) Tampas de bambu para o início da filtragem. Fonte: Autores (2016).

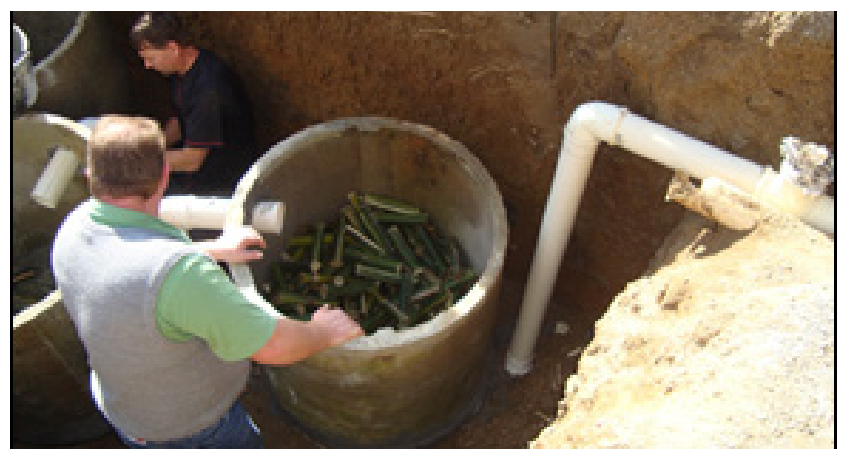

Figura 4 - Pequenos pedaços de PVC no primeiro tubo. Fonte: Autores (2016)

O terceiro tubo consiste numa mistura de filtro de bambu e filtro de areia e brita. Isso ocorre para um melhor resultado na fermentação do efluente. Segundo pesquisas e testes feitos pela Epagri, em 2010, apenas um reator não alcançou resultados satisfatórios, então foi incluído um filtro a mais com areia e brita para melhorar os resultados obtidos.

As figuras 5 (a) a (d) ilustram a execução do terceiro tubo. Após, o filtro de pequenos pedaços de bambu, é inserido uma tela fina, para evitar o contato da areia com o bambu. Então, é inserido uma camada de aproximadamente $15 \mathrm{~cm}$ de brita número 2 e uma fina camada de areia. Por fim, é colocada a tampa de concreto no tubo, que já está ligado à drenagem da rua, por uma tubulação de PVC. 

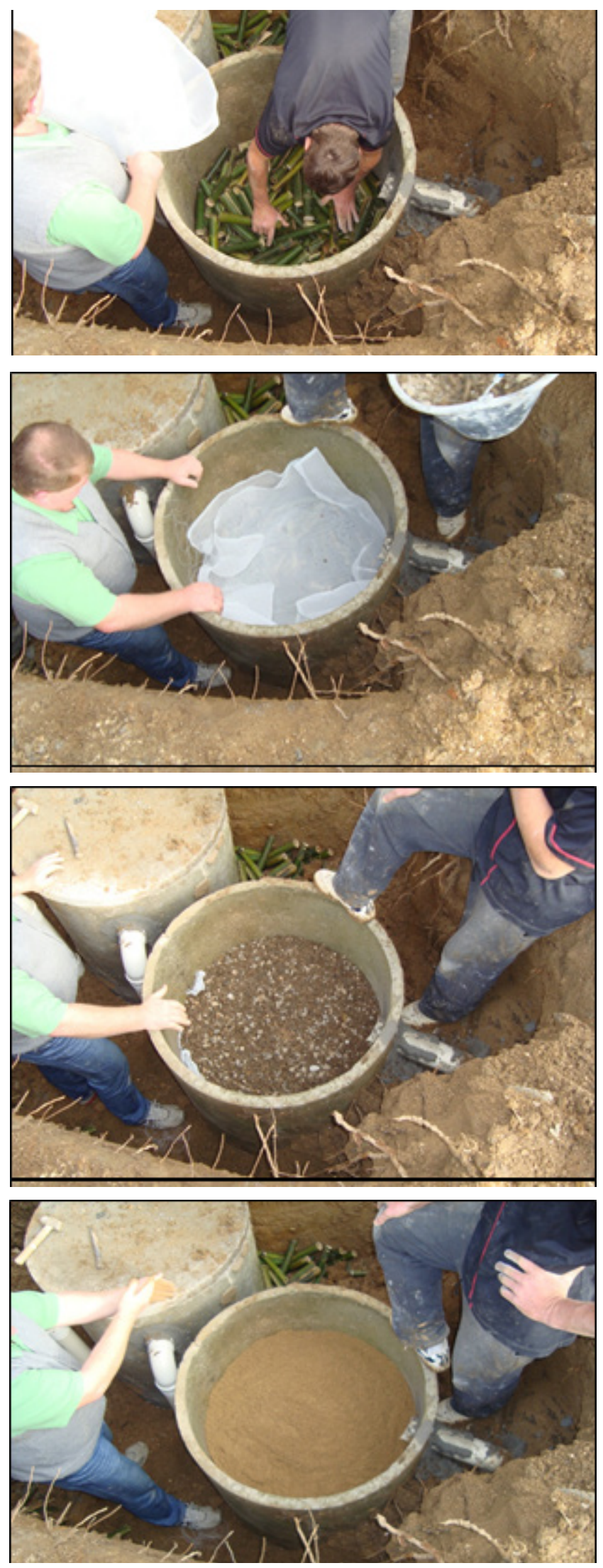

Figura 5 - (a) Filtro de bambu no último tubo; (b) Tela para separação da areia e bambu; (c) Colocação da brita número 2; (d) Colocação da camada de areia fina. Fonte: Autores (2016).
Por fim, após a colocação da tampa de concreto no último tubo, o processo de execução do tratamento está concluído, podendo assim cobrir a vala com areia. A figura 6(a) mostra o tratamento pronto e a figura 6(b) à ligação do tratamento com a drenagem urbana.
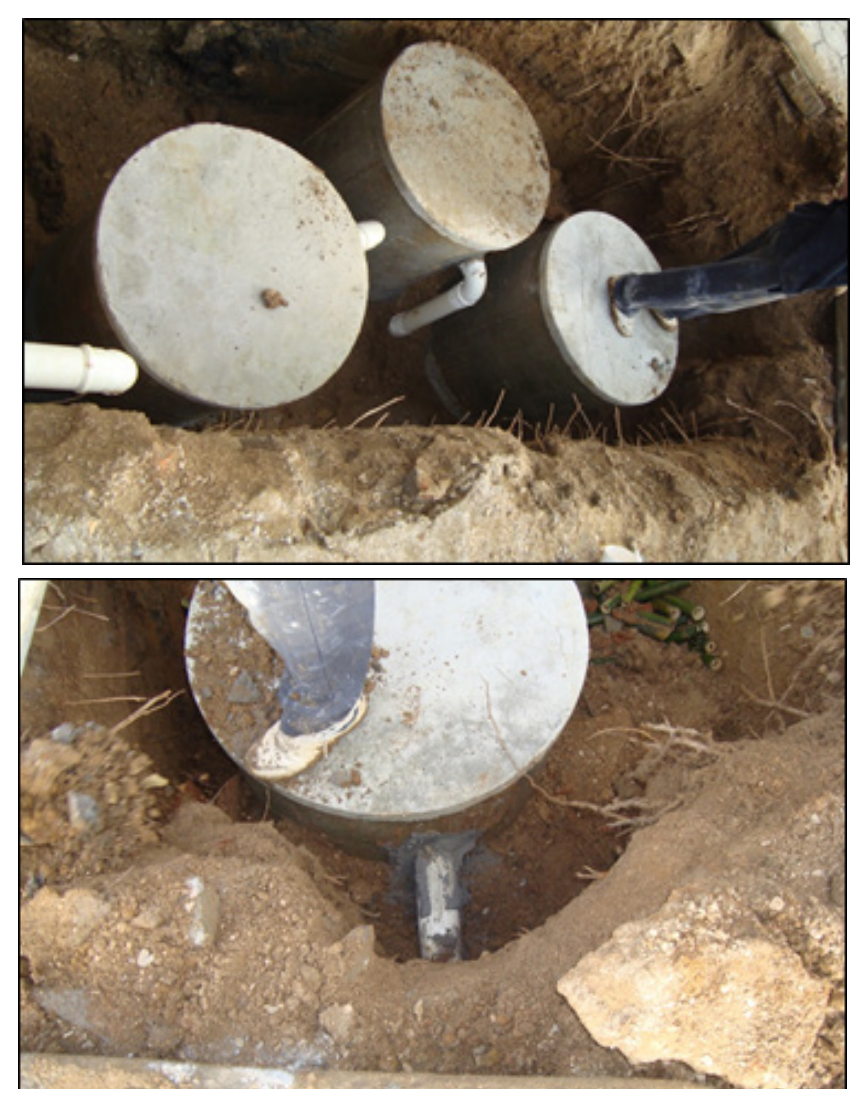

Figura 6 - (a) Execução concluída; (b) Ligação do tratamento até a drenagem da rua. Fonte: Autores (2016).

\subsection{Parâmetros da qualidade da água}

Para verificar os resultados do tratamento alternativo foram coletadas amostras dos dois tipos de tratamento de efluentes e analisadas em laboratório, a partir dos seguintes parâmetros: $\mathrm{pH}$; Cor; Turbidez; DBO; DQO. A coleta foi feita pela manhã e dentro de, no máximo, 3 horas entregue ao laboratório contratado para análises químicas. Durante a coleta usou-se um recipiente esterilizado para armazenar o material e para realizar a coleta. $O$ processo foi repetido por três semanas seguidas.

\subsection{Coleta no tratamento com filtro de bambu}

A coleta foi realizada em uma residência unifamiliar de aproximadamente $100 \mathrm{~m}^{2}$ onde moram 4 pessoas, todos adultos. Neste caso, a drenagem pluvial passa na rua e o efluente é jogado diretamente nesta. A coleta deste material precisou um pouco mais de cuidados, pois foi necessário realizar a escavação até o cano, cortar um 
pedaço pequeno deste cano para então realizar a coleta. Para não prejudicar a qualidade do efluente, uma lavagem com água limpa ao redor do tubo é feita anteriormente à coleta. Com alguns panos é feito uma barreira para trancar a passagem do efluente e então é realizada a coleta. As figuras 7 (a) a (c) ilustram o processo de coleta e o efluente coletado.
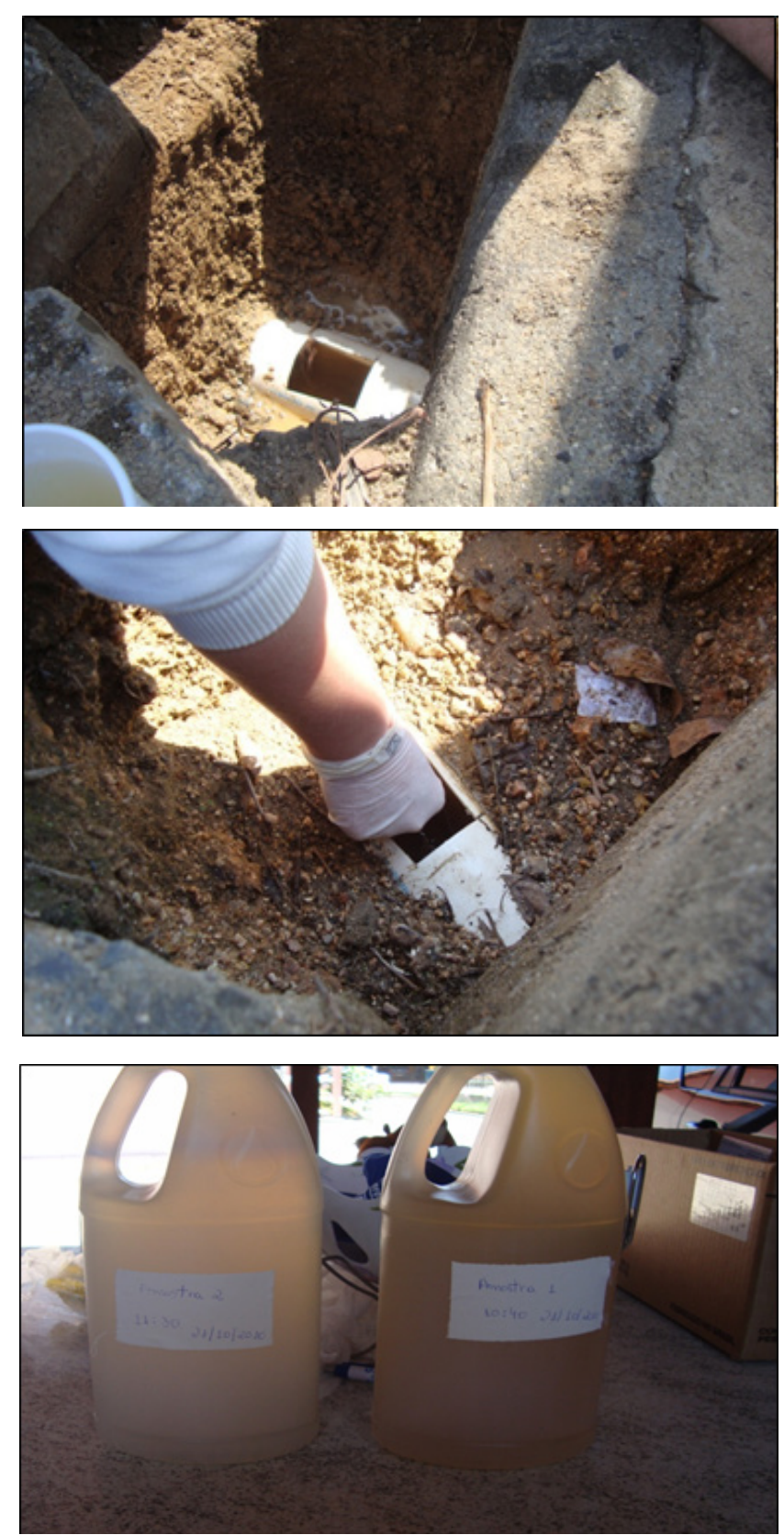

Figura 7 - (a) Local da Coleta Tratamento Alternativo; (b) Material sendo coletado; (c) Amostras prontas para seguir para o laboratório.

Fonte: Autores (2016).

\subsection{Coleta no tratamento convencional}

A coleta foi realizada em uma residência unifamiliar com aproximadamente $300 \mathrm{~m}^{2}$, onde residem três pessoas, dois adultos e uma criança. $O$ tratamento possui dimensões de $(3,0 \times 2,5) \mathrm{m}$, fossa e filtro anaeróbico. A rua onde está localizada a residência, não possui drenagem pluvial, logo o efluente sai diretamente na rua através de um cano de PVC. As figuras 8 (a) a (c) mostram o local de coleta e como são feitas as coletas, seguidas do material com identificação.
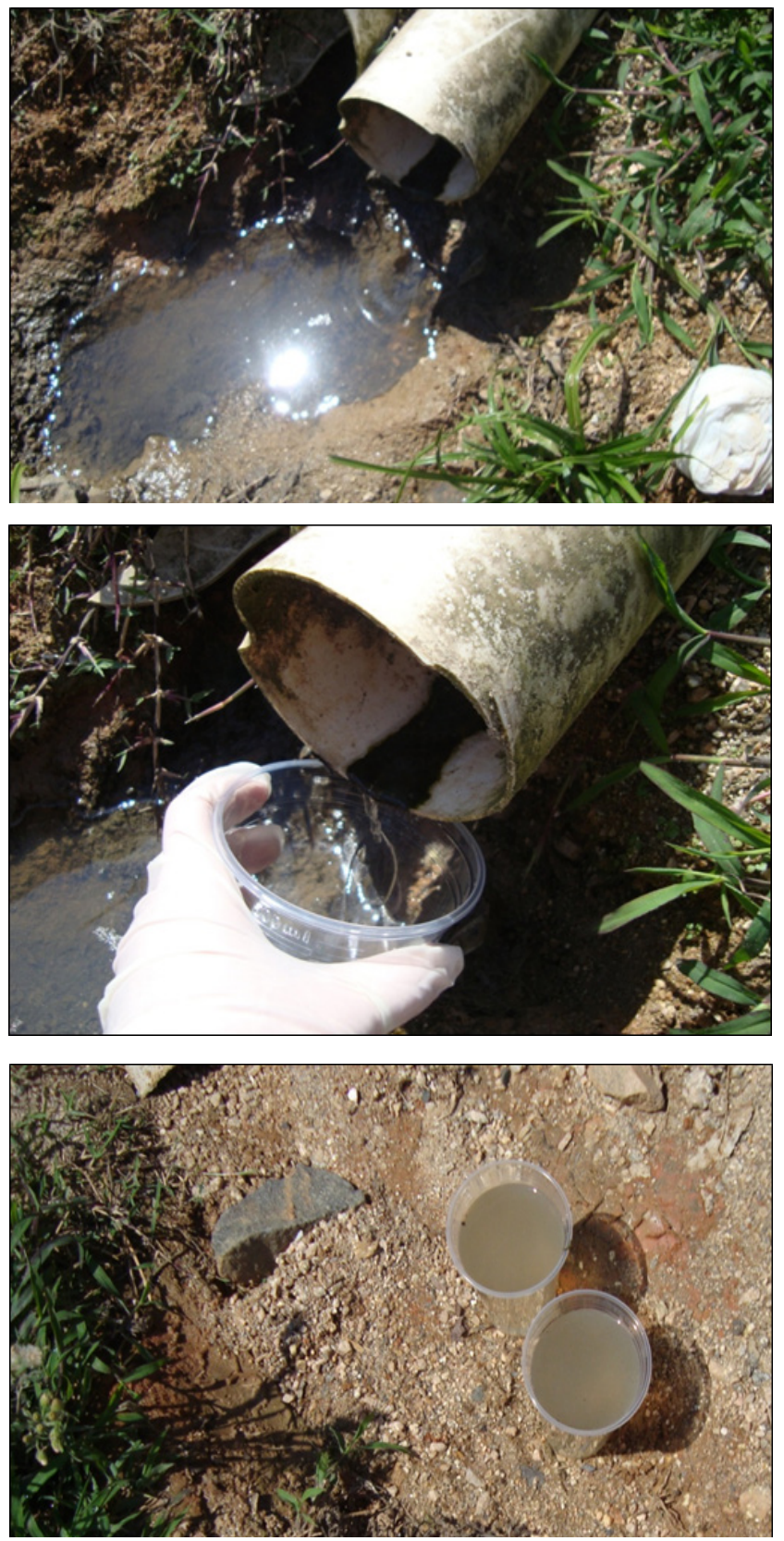

Figura 8 - (a) Local de Coleta do Tratamento Convencional (Fossa e Filtro); (b) Coleta do efluente do tratamento convencional; (c) Material Coletado. Fonte: Autores (2016). 


\section{RESULTADOS E DISCUSSOES}

\subsection{Comparação entre os custos de execução do filtro de bambu e o tratamento convencional}

Um dos fatores a ser considerado na hora da escolha do sistema de tratamento de esgoto doméstico é o custo de implantação, além de sua eficácia. E, em sua maioria, por ter um elevado custo em materiais e mão de obra, normalmente não é executado e o efluente doméstico é descartado sem qualquer tratamento. Nas tabelas $1 \mathrm{e}$ 2 é apresentado os valores de cada tipo de tratamento para uma avaliação financeira sobre a execução do sistema. Os valores foram retirados com base na tabela do Sistema Nacional De Pesquisa de Custos e Índices da Construção Civil (SINAPI).

\begin{tabular}{|l|l|l|l|l|l|}
\hline \multicolumn{6}{|c|}{ Planilha orçamento fossa séptica/filtro anaeróbico (modelo } \\
que atende as normas ABNT - NBR 7229/93 e NBR 13969/97)
\end{tabular}

Tabela 1 - Valores Fossa Séptica/Filtro Anaeróbico

Fonte: Autores (2016)

\begin{tabular}{|l|l|l|l|l|l|}
\hline \multicolumn{6}{|l|}{ Planilha orçamento reator com filtro e bambu } \\
\hline ITEM & Descrição & UNIDADE & QTIDADE & PREÇO & TOTAL \\
\hline 1 & $\begin{array}{l}\text { Escavação } \\
\text { de Solo }\end{array}$ & $\mathrm{m}^{3}$ & 9,0 & 14,14 & 127,60 \\
\hline 2 & Kit Fossa Septica & Um & 3,0 & 180,00 & 540,00 \\
\hline 3 & Areia Fina & $\mathrm{M}$ & 0,5 & 70,00 & 35,00 \\
\hline 4 & Brita N2 & $\mathrm{M}$ & 0,5 & 57,50 & 28,75 \\
\hline 5 & $\begin{array}{l}\text { Tubo de Esgoto } \\
100 \mathrm{~mm}\end{array}$ & $\mathrm{Br}$ & 2,0 & 8,05 & 16,10 \\
\hline 6 & $\begin{array}{l}\text { Joelho } \\
90-100 \mathrm{~mm}\end{array}$ & Pç & 5,0 & 4,94 & 24,70 \\
\hline
\end{tabular}

\begin{tabular}{|l|l|l|l|l|l|}
\hline 7 & $\begin{array}{l}\text { Te Esgoto } \\
-100 \mathrm{~mm}\end{array}$ & Pç & 1,0 & 5,29 & 5,29 \\
\hline 8 & $\begin{array}{l}\text { Luva Esgoto } \\
100 \mathrm{~mm}\end{array}$ & Pç & 3,0 & 4,16 & 12,48 \\
\hline 9 & $\begin{array}{l}\text { Luna Esgoto } \\
50 \mathrm{~mm}\end{array}$ & Pç & 2,0 & 1,93 & 3,86 \\
\hline 10 & Fita Veda Rosca & Pç & 2,0 & 7,19 & 14,38 \\
\hline 11 & $\begin{array}{l}\text { Redução } \\
100 x 50 \mathrm{~mm}\end{array}$ & Pç & 2,0 & 1,89 & 3,78 \\
\hline
\end{tabular}

Tabela 2 - Valores Reator com Filtro de Bambu Fonte: Autores (2016).

Como mostram os dados apresentados nas tabelas 1 e 2, os custos do sistema de tratamento convencional (Fossa Séptica/Filtro Anaeróbico) é 25\% mais elevado em relação ao custo do sistema alternativo. $O$ custo para a montagem do tratamento convencional possui materiais de custo mais elevado que o sistema alternativo, além do valor da mão de obra que o encarece ainda mais, uma vez que, o modelo alternativo, não possui acréscimos com mão de obra, por ser de simples execução.

\subsection{Avaliação Química}

Com o objetivo de se conhecer os valores obtidos com o tratamento de esgoto alternativo e comparar com os valores determinados pelos órgãos competentes, foram realizadas quatro coletas de material na saída do processo, em semanas subsequentes, e enviadas para o laboratório de análises químicas contratado. $O$ resultado obtido está apresentado na tabela 3 .

\begin{tabular}{|l|l|l|l|l|}
\hline Análises & Coleta 1 & Coleta 2 & Coleta 3 & Coleta 4 \\
\hline $\mathrm{PH}$ & 8,08 & 7,91 & 7,82 & 7,79 \\
\hline Cor, mg/L de Pt & 163,30 & 148,0 & 186,5 & 165,6 \\
\hline Turbidez, FAU & 54,0 & 48,0 & 71,0 & 59,0 \\
\hline
\end{tabular}

Tabela 3 - Análise do efluente obtido no Tratamento Alternativo Fonte: Autores (2016).

A mesma análise foi realizada em um processo convencional (fossa/filtro) para se conhecer os valores obtidos através de métodos normalmente utilizados pelas comunidades. A tabela 4 mostra o resultado para o processo convencional.

\begin{tabular}{|l|l|l|l|l|}
\hline Análises & Coleta 1 & Coleta 2 & Coleta 3 & Coleta 4 \\
\hline $\mathrm{PH}$ & 7,36 & 7,39 & 7,52 & 7,51 \\
\hline Cor, mg/L de Pt & 171,0 & 71,1 & 128,8 & 119,9 \\
\hline Turbidez, FAU & 113,0 & 26,0 & 61,0 & 52,0 \\
\hline
\end{tabular}

Tabela 4 - Análises do efluente obtido no Tratamento Convencional Fonte: Autores (2016). 
Sobre o pH, a Resolução do CONAMA N³57/2005, Artigo 34, parágrafo IV, determina que só se poderá lançar efluentes em corpos de água com pH entre 5 e 9. A mesma resolução também determina que para rio classificado como de classe II (águas que podem ser destinadas ao abastecimento para consumo humano), a cor deve ser de até $75 \mathrm{mg} / \mathrm{L}$ de Pt e a turbidez de até 100 FAU.

Logo, no parâmetro $\mathrm{pH}$, os dois tratamentos estão dentro do limite permitido. Sabe-se que o $\mathrm{pH}$ pode ser alterado se há chuva $48 \mathrm{~h}$ antes da coleta. Então vale ressaltar que todas as coletas foram feitas em dias que o tempo estava estável, sem possibilidade de chuvas. Quanto a cor, para o tratamento alternativo todas as medidas passaram do valor permitido. No tratamento convencional, apenas em uma coleta o valor se mostrou adequado. Podemos comentar que a cor pode ser inconstante dependendo da forma de coleta, uso do sistema no período entre outros fatores. Sobre a turbidez, os dois tratamentos atendem ao padrão exigido.

Além desses parâmetros, a determinação das taxas de operação de uma estação de tratamento de esgotos sanitários é feita normalmente a partir da análise de características como demanda bioquímica de oxigênio - DBO, demanda química de oxigênio - DQO, entre outros. Deve ser acrescentado que, segundo Giansante (2002), dados operacionais de concessionárias brasileiras de saneamento apontam que a relação usual DQO/ DBO está por volta de 1,7 no máximo, quando se trata de esgotos domésticos. Assim, valores superiores a este, devem servir como alerta a razão limite DQO/DBO igual 3,0, dada à provável presença de componentes tóxicos que inibem os microrganismos responsáveis pelo tratamento de esgotos.

A tabela 5 mostra a razão entre DQO/DBO, feitas no tratamento alternativo e convencional.

\begin{tabular}{|l|l|l|l|l|}
\hline Análises & Coleta 1 & Coleta 2 & Coleta 3 & Coleta 4 \\
\hline $\begin{array}{l}\text { Tratamento } \\
\text { Alternativo }\end{array}$ & 16,18 & 1,87 & 1,32 & 1,10 \\
\hline $\begin{array}{l}\text { Tratamento } \\
\text { Convencional }\end{array}$ & 1,90 & 2,7 & 2,54 & 2,05 \\
\hline
\end{tabular}

Tabela 5 - Razão DQ0 /DB0 no Tratamento Alternativo e no convencional. Fonte: Autores (2016).

Observa-se que valor da coleta 1 no tratamento alternativo, está alto pois a DBO chegou ao resultado de apenas $10 \mathrm{mg} / \mathrm{L}$. Com essa exceção, todos os valores não ultrapassaram o valor limite de referência $(3,0)$, pois estão próximos a 1,7, livres de prováveis presenças de componentes tóxicos nos locais de lançamento.
No tratamento convencional observa-se que todos os valores ficaram abaixo do valor limite de referência $(3,0)$, mas vale ressaltar que, com exceção da coleta 1, todos deram próximos ao mesmo.

Devemos também, destacar que a saída de um esgoto doméstico depende muito da movimentação da residência, quantidade de pessoas, dentre outros fatores. As informações acima, não foram conclusivas, em relação ao melhor tratamento. Para esta avaliação, seria necessária uma série de análises e estudos, por mais tempo e durante as diferentes estações do ano. Mas já se nota o indicativo da validade do método alternativo.

\subsection{Educação Ambiental na elaboração do material}

Com o intuito de promover a Educação Ambiental no município de Rio Fortuna, uma cartilha foi elaborada levando em consideração a importância para a saúde, o bem estar da população e a praticidade na implantação do sistema alternativo, mostrando que é possível encontrar soluções para o problema da falta de saneamento básico.

A Educação Ambiental é essencial na compreensão sobre a falta de saneamento, seus riscos e como melhorar as condições do meio em que se vive. Quando este entendimento é alcançado, percebe-se que soluções podem ser propostas e abre-se uma ampla oportunidade de melhorar as condições de vida e saúde dos habitantes no município. A Educação Ambiental é o processo transformador que agirá diretamente na população, modificando questões sociais e econômicas.

A cartilha demonstrará os passos da execução do tratamento alternativo com filtro de bambu, feito a partir do material registrado durante a execução do sistema, com detalhamentos sobre dimensionamento e funções de cada material. Deve ainda especificar os materiais utilizados e fazer uma breve comparação sobre custos dos dois tratamentos. Deve mostrar também que o tratamento alternativo pode ser uma solução para o problema.

Levando em consideração que o município de Rio Fortuna possui uma população pequena e que seu problema de saneamento é grave, principalmente na zona rural, a cartilha se expressa de maneira simples para a compreensão de todos, possuindo uma grande quantidade de ilustrações. Ainda de maneira simples, alerta para os riscos que a falta de saneamento básico gera para a saúde e o bem estar dos habitantes.

Por ser uma ferramenta de fácil compreensão, a cartilha sobre saneamento básico e execução de um tratamento alternativo é algo essencial a ser realizado no 
município. A Educação Ambiental sobre o tratamento de esgoto alternativo deve promover a tomada de consciência a respeito dos problemas ambientais existentes para que gere uma mobilização da população. Essa tomada de consciência deve também se estender à compreensão da necessidade e à busca de formas alternativas de relação com o meio, envolvendo atitudes favoráveis à cooperação coletiva para a solução dos problemas ambientais.

Entretanto, sabendo que a consciência sobre os problemas ou necessidades, assim como as atitudes positivas dela procedentes, pode ser um fenômeno passageiro, é preciso persistência e clareza nos métodos utilizados para a divulgação para que a população se mantenha informada.

Este material possui a vantagem ainda de promover o crescimento sustentável do município, ou seja, saber usar os recursos naturais para satisfazer as nossas necessidades, sem comprometer as necessidades e aspirações das gerações futuras, ou seja, saber usar para nunca faltar. $E$ isso não exige um grande esforço, somente mais atenção com o que está ao nosso redor, no nosso ambiente. Isso tem relação com o uso da água, o consumo do papel, seja em casa ou no trabalho, o consumo de energia elétrica, destinação correta do lixo, reciclagem e redução ou eliminação do desperdício. $O$ tratamento com filtro de bambu possui essas características, possuindo a facilidade de obtenção de materiais.

A divulgação do material e da Educação Ambiental no município de Rio Fortuna deve ser feita através da ajuda de órgãos públicos, colaborando na organização de palestras para a explicação e distribuição da cartilha (Figura 9 (a) a (e)). Além disso, com a ajuda da Prefeitura Municipal, a distribuição poderá acontecer através de agentes de saúde, que fazem monitoramento a cada mês, em todas as residências do município e diretamente com a vigilância sanitária, disponibilizando a cartilha para os interessados. O material também poderá ser disponibilizado em algum endereço eletrônico vinculado ao município.

\section{CONSIDERAÇÕES FINAIS}

Os resultados indicam que o tratamento estudado mostrou grande potencial de eficácia para atender as necessidades em saneamento da população do município de Rio Fortuna, bem como para outras pequenas comunidades. Os custos mais baixos e a facilidade na execução indicam o sistema alternativo como uma alternativa atrativa de solução ao problema.

Com relação às análises químicas, o pH do tratamento alternativo se mostrou dentro valor esperado, e a relação DBO/DQO está dentro do previsto, mostrando que pode ser utilizado como tratamento para esgoto doméstico.
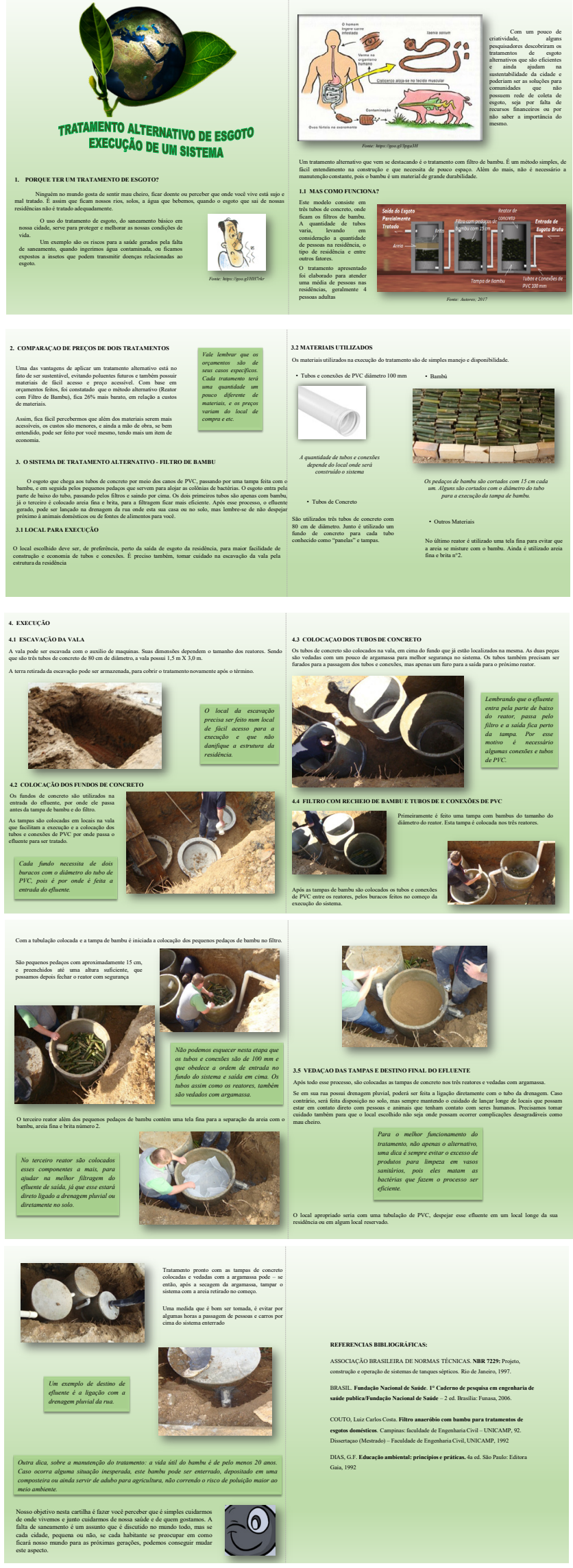

Figura 9 (a) a (e) - Cartilha proposta para Educação Ambiental. Fonte: Autores (2016). 
O trabalho, no entanto, foi além de uma análise técnica, uma vez que abordou questões educativas importantes à sociedade. A falta de saneamento básico, a carência de conhecimento e conscientização da população sobre o assunto, a importância dos métodos alternativos para tratamentos de resíduos e principalmente a importância da Educação Ambiental em uma comunidade, foram discutidos. Percebe-se que a abordagem da Educação Ambiental por meio da cartilha promoverá o interesse da população pelo problema, além de mostrar como uma solução pode ser simples. O material também promove discussões sobre cidadania, sobre o direito à saúde e a um ambiente mais saudável, essenciais para a promoção da saúde e para a sustentabilidade ambiental.

Conclui-se que a aliança entre o Saneamento Básico e a Educação Ambiental é fundamental como estratégia nas atuais abordagens das questões de saúde pública, meio ambiente e sustentabilidade, sem a qual estes processos não seriam alcançados.

\section{REFERÊNCIAS}

AISSE, M. M.; Sistemas econômicos de tratamento de esgotos sanitários (192 P) Rio de Janeiro: ABES. 2000 ASSOCIAÇÃO BRASILEIRA DE NORMAS TÉCNICAS. NBR 13969: Tanques Sépticos - Unidades de tratamento complementar e disposição final dos efluentes líquidos - Projeto construção e operação; Rio de Janeiro, ABNT. 1997.

ASSOCIAÇÃO BRASILEIRA DE NORMAS TÉCNICAS. NBR 7229: Projeto, construção e operação de sistemas de tanques sépticos. Rio de Janeiro, ABNT. 1993

BOLSCHO, D.; HAUENSCHILD, K. From environmental education to education for sustainable development in Germany: the state of the art, Environmental Education Research, volume (12), número (1), p.7-18, 2006, https://doi.org/10.1080/13504620500526487

BRASIL. Fundação Nacional de Saúde. FUNASA. $1^{\circ}$ Caderno de pesquisa em engenharia de saúde pública/Fundação Nacional de Saúde - 2 ed. Brasília: Funasa. 2013.

BRASIL. Lei n 11.445, de 05 de janeiro de 2007. Lei do Saneamento Básico. recuperado em 25 setembro 2010 de http://www.planalto.gov.br/ccivil_03/_ato20072010/2007/lei/l11445.htm.

BRASIL. Resolução do CONAMA n 357/2005. "Dispõe sobre a classificação dos corpos de água e diretrizes ambientais para o seu enquadramento, bem como estabelece as condições e padrões de lançamento de efluentes, e dá outras providências." - Publicação DOU n० 053, de 18/03/2005, p. 58-63. Recuperado em: 09 nov. 2010. de: http://www.mma.gov.br/port/conama/ legiabre.cfm?codlegi $=459$

BRITO, E.R., PINHO, P.S., RIBEIRO, A. Prolegômenos do filtro biológico de bambu. In: Anais do 9凶 Congresso de Engenharia Sanitária (p.1-34). Belo Horizonte: ABES. 2007

CAMPOS, P. C. Meio ambiente; a sustentabilidade passa pela educação (em todos os níveis, inclusive pela mídia). Revista em Questão. Volume (12), número (2), 387-419. ISSN 1808-5245; 2006.

DIAS, F. S., NASCIMENTO, J. P. A., MENESES, J. M. Aplicação de macrófitas aquáticas para tratamento de efluente doméstico; Revista Ambiental. Volume (2), número (1), 106 -115. ISSN: 2446-6743; 2016

DIAS, G.F.; Educação ambiental: princípios e práticas. 4a ed. São Paulo: Editora Gaia; 2002

FAGUNDES, R.M., SCHERER, M. J. Sistemas alternativos para o tratamento local dos efluentes sanitários; Série: Ciências Naturais e Tecnológicas, volume (10), número (1), 53-65. ISSN 1981-2841; 2009.

FENG, H.; HU, L., MAHMOOD, Q., QIU, C., FANG, C., SHEN, D. Anaerobic domestic wastewater treatment with bamboo carrier anaerobic baffled reactor; International Biodeterioration \& Biodegradation; Volume (62), Issue (3), 232-238; 2008. https://doi.org/10.1016/j.ibiod.2008.01.009

FONTES, A.R., BASTOS, R.P. N., SANTOS, M. B. S. Condições socioambientais de saneamento básico no conjunto Santa Terezinha, Bairro Novo Horizonte, Lagarto (SE): desafios frente à educação ambiental; Revista Brasileira de Educação Ambiental,Volume (12), Número (1), 97-114. ISSN 1981-1764; 2017.

GARCIA, M.S.D.; FERREIRA, M. P. Saneamento básico: meio ambiente e dignidade humana; Dignidade ReVista, Número (3), ISSN 2525-698X; 2017

GIANSANTE, A.E.; A variação de relação DQO/ DBO em esgotos sanitários - o caso da ETE Jundiaí. In VI Simpósio Ítalo Brasileiro de Engenharia Sanitária e Ambiental (p. 1-3), Vitória. 2002.

IBGE. Instituto Brasileiro de Geografia e Estatística. Censo demográfico - 2010. Rio de Janeiro. IBGE. Recuperado em: 12 Set. 2010. De http://www.ibge.gov. br/home/mapa_site/mapa_site.php\#populacao IORIO, S. M., ARCE, D. M., MAGALHÃES, J.; MATTOS, A. B., ZANON, A. M. A perspectiva da educação ambiental e o processo histórico do saneamento básico: a instalação das redes de água e esgoto nos municípios de Campo Grande/MS e Dourados/MS, Revista 
Interações, volume (10), número (1); 2009. http://dx. doi.org/10.1590/S1518-70122009000100007.

LISBÔA, L.L.; JUNQUEIRA, H.; DEL PINO, J. C., Histórias em quadrinhos como material didático alternativo para o trabalho de educação ambiental; Gaia scientia. Volume (2), número (1), 29-39, ISSN 1981-1268; 2009 MACHADO, J. R.M.; UCKER, F.E.; SILVA JUNIOR, M. G.; ALONSO, R.R.P., Situação do saneamento básico no bairro vila mutirão na cidade de GOIÂNIA-GO; Revista Eletrônica de Educação da Faculdade Araguaia, Número (8), 104-145, ISSN: 2236-8779; 2015.

MIELBRATZ, M., DOLZAN, M. V.; O tratamento de esgotos e dejetos em propriedades rurais sustentáveis; Revista Maiêutica, volume (4), número (1), 75-82, 2016 MESQUITA, M. O.; TREVILATO, G. C.; SARAIVA, L.H.; SCHONS, M. S.; GARCIA, M.I. F., Material de educação ambiental como estratégia de prevenção da leptospirose para uma comunidade urbana reassentada; $\mathrm{Cad}$. Saúde Colet., volume (24), número (1): 77-83; 2016. http://dx.doi.org/10.1590/1414-462X2016000x0428 PINTO, L.M.; MAGALHÃES, G.M.; SPALLETTI, L.T. Sistema de filtros de águas cinzas como ferramenta de Educação Ambiental na comunidade de São Miguel - Paranaguá- PR, no âmbito do monitoramento ambiental da Dragagem de Manutenção dos Portos de Paranaguá e Antonina; In Anais do VI Encontro Nacional de Pós-Graduação, (p. 162-171), Santa Cecília. 2017

QUEGE, K.E., ALMEIDA, R. A., UCKER, F.E., Utilização de plantas de bambu no tratamento de esgoto sanitário pelo sistema de alagados construídos; Rev. Elet. em Gestão, Educação e Tecnologia ambiental; voume(10), número (10), 2069-2080; 2013 http://dx.doi. org/10.5902/223611707440.

SILVA, M. M. P.; SOUSA, J.T.; CEBALLOS, B. S. O.; LEITE, V.D.; FEITOSA, W. B. S., ARAÚJO, E. A. A., Educação Ambiental: Instrumento para sustentabilidade de tecnologias para tratamento de lodos de esgotos; Rev. eletrônica Mestr. Educ. Ambient. Volume (23), ISSN 1517-1256. 2009

SINAPI. Índices da Construção Civil. Recuperado em 09 Nov. 2010. De http://www1.caixa.gov.br/gov/gov_so$\mathrm{cial} /$ municipal/programa_des_urbano/SINAPI/index. asp.

SOUZA, R. C.; ISOLDI, L.A.; OLI, C.M. Tratamento de esgoto doméstico por filtro anaeróbico com recheio de bambu; Revista Vetor, Rio Grande, volume (20), número (2), 5-19; 2010

TRITT, W. P., ZADRAZIL, F., MENGE-HARTMANN, U.,
SCHWARZ, S.; Bamboo as a support material in anaerobic reactors. World Journal of Microbiology and biotechnology. Volume (9), 229 -232, 2003; http://dx. doi: 10.1007/BF00327844. 


\section{AUTORES}

ORCID: 0000-0002-1050-0178

HELOISA REGINA TURATTI SILVA; Dra. | Ciencia e Engenharia dos Materiais | Universidade do Sul de Santa Catarina, Engenharias | Pedra Branca; Palhoça/SC - Brasil | Av Pedra Branca 25 - Laboratório de fisica - Bloco L (Engenharias), 88137-272 | Email: helofloripa2004@yahoo.com.br

ORCID: http://orcid.org/0000-0001-8458-9972

PAOLA EGERT, Dra. | Ciencia e Engenharia dos Materiais | Universidade do Sul de Santa Catarina, Engenharias | Pedra Branca; Palhoça/SC - Brasil | Av Pedra Branca 25 Laboratório de fisica - Bloco L (Engenharias), 88137-272 | Email: paola.egert.ortiz@gmail.com

MARIA IZABEL WILlemanN | Universidade do Sul de Santa Catarina, Engenharias | Pedra Branca; Palhoça/SC - Brasil | Av Pedra Branca 25 - Laboratório de fisica - Bloco L (Engenharias), 88137-272 | Email: mariaizabelw@gmail.com

\section{COMO CITAR ESTE ARTIGO}

SILVA, Heloisa Regina Turatti; EGERT, Paola; WILLEMANN, Maria Izabel. Avaliação De Um Sistema Alternativo Para Tratamento De Efluente Doméstico $\mathrm{E}$ Planejamento Para Conscientização Da Comunidade. MIX Sustentável, [S.I.], v. 7, n. 2, p. 67-78, abr. 2021. ISSN 24473073. Disponível em:<http://www.nexos. ufsc.br/index.php/mixsustentavel>. Acesso em: dia mês. ano. doi:https://doi.org/10.29183/2447-3073. MIX2021.v7.n2.67-78.

DATA DE ENVIO: 06/08/2020

DATA DE ACEITE: $12 / 11 / 2020$ 